\title{
Feminismo, diversidad sexual y relaciones sexo-afectivas disidentes. Apuestas y tensiones en el PST, 1971-1975
}

\author{
Catalina Trebisacce y Martín Mangiantini \\ IIEGE-FFyL-UBA, Conicet / ISP Joaquín V. González - UBA \\ catalinaptrebisacce@gmail.com / martinmangiantini@gmail.com
}

El presente trabajo tiene como objetivo abordar la dinámica de una organización revolucionaria trotskista, el Partido Socialista de los Trabajadores (en adelante, PST), entre 1971 y 1975, en lo pertinente a tres temáticas entrelazadas: la militancia feminista sostenida durante esos años, las concepciones esgrimidas con relación a la homosexualidad y la problematización en torno a las relaciones sexo-afectivas y familiares dentro de la dinámica partidaria.

El período de análisis se inscribe en el contexto de las postrimerías del Cordobazo en un escenario de radicalización política y de proliferación de organizaciones militantes, tanto de estructuras partidarias de diversa extracción ideológica como de nuevos movimientos sociales. En el marco de un profundo cuestionamiento a la estructura económica, política y social de la Argentina, surgieron fenómenos como el clasismo en el movimiento obrero, una juventud radicalizada y antiimperialista y el giro a la izquierda de colectivos intelectuales. En coincidencia con este clima de agitación social, se conformaron grupos de militancia feminista y gay que se focalizaron especialmente en dar una batalla cultural contra los discursos en boga en torno a la sexualidad y al rol de la mujer. En apariencia, la izquierda orgánica no manifestó mayor interés por intervenir en estos campos, sin embargo el PST fue una de las excepciones. El presente artículo pretende exponer las caracteristicas que tuvo la politica desarrollada por este partido alrededor de las problemáticas mencionadas, sosteniendo que las mismas se constituyeron en un signo identitario que lo diferenció del conjunto de las organizaciones revolucionarias existentes.

El PST fue la continuidad como partido político de una corriente trotskista iniciada en la Argentina en los años 40 encabezada por la figura

(Archivos, año IV, $\mathrm{n}^{\circ} 7$, septiembre de 2015, pp. 101-120) 
de Nahuel Moreno con la creación del Grupo Obrero Marxista (luego Partido Obrero Revolucionario) impulsado por un puñado de jóvenes que pugnaron insertarse en la clase obrera porteña y bonaerense. En su derrotero, se integró al Partido Socialista de la Revolución Nacional (un desprendimiento del viejo socialismo) y, tras el golpe de Estado que derribó al gobierno peronista en 1955, su principal acción se desenvolvió dentro del movimiento obrero que resistió a la dictadura a través de la práctica del entrismo en el peronismo. En estos años, la corriente adoptó el nombre de Palabra Obrera, que utilizó hasta 1965 cuando, tras unirse al FRIP de los hermanos Santucho, conformó el Partido Revolucionario de los Trabajadores (PRT) cuya corta existencia se extendió hasta 1968 al producirse la ruptura de la organización siendo el ala de Moreno la que dinamizaría el PRT La Verdad (PRT-LV). A finales de 1971, este partido inició un proceso de transformación que concluyó en la unión con el Partido Socialista Argentino dirigido por Juan Carlos Coral, fusión de la que surgió el PST.

La elección del periodo 1971-1975 responde tanto a la coyuntura argentina como a la dinámica de esta corriente. En 1971 se inició el proceso de transición del PRT-LV al PST, que significó un crecimiento cuantitativo, la búsqueda de inserción de la organización a nivel nacional y la transformación de la herramienta revolucionaria en una variante también electoral acorde al proceso de democratización que se abría paulatinamente con la crisis definitiva del proyecto castrense iniciado en 1966. De hecho, en los años abordados en este artículo, esta corriente pasó de poseer entre 300 y 400 militantes a cifras cercanas a los dos mil. Fue justamente en este proceso cuando profundizó el sostenimiento de nuevas temáticas.

$\mathrm{El}$ artículo se estructura en cuatro secciones. La primera repasa los rasgo identitarios del PST lo que, en parte, explica el interés por las temáticas que seguirán a continuación. El segundo apartado trabaja sobre el desarrollo de su militancia feminista. El tercero se ocupa de las concepciones que se elaboraron (aunque no siempre se hicieron públicas) en torno a la homosexualidad y, finalmente, se presentan las experiencias de relaciones sexo-afectivas disidentes con las que algunos militantes del PST se comprometieron.

\section{Los rasgos identitarios del PST}

Una de las características más relevantes del período abordado recae en la existencia de una proliferación de organizaciones políticas autodefinidas como revolucionarias. Se trató del surgimiento de agrupamientos de izquierda críticos del Partido Socialista y del Comunista, como lo fueron Política Obrera, Vanguardia Comunista o el Partido Comunista 
Revolucionario. Al mismo tiempo, se produjo el desarrollo de organizaciones revolucionarias simultáneamente políticas y militares, como el PRT-ERP, la Organización Comunista Poder Obrero y las Fuerzas Argentinas de Liberación, entre otras. Este abanico de organizaciones se complementó con aquellas corrientes que trataban de conjugar la posibilidad del socialismo con el peronismo tales como las Fuerzas Armadas Peronistas y, principalmente, Montoneros. Ante tal multiplicación de organizaciones, resulta imperiosa la pregunta sobre las características específicas del PST: qué significado le daba su militancia al hecho de formar parte de esta corriente y qué aspectos propios de su estructura eran percibidos como una marca de identidad para sus miembros en contraposición a las características del conjunto de organizaciones existentes en la misma época.

Toda construcción identitaria es resultado del movimiento simultáneo de afirmación y negación y supone el establecimiento de definiciones, posicionamientos, y hasta elecciones estéticas, que conllevan necesariamente distanciamientos y oposiciones respecto de otros. Por ello la identidad que construyó este partido supuso la adopción de determinados valores, ideas y conductas en detrimento de otras posibles. En diversas oportunidades, los valores defendidos por la militancia del PST se identificaban por la negativa, es decir, por la decisión de no sostener prácticas ponderadas como nocivas para el ideal del militante revolucionario que sí eran costumbre en otras estructuras.

En el período abordado pueden identificarse, por lo menos, cuatro rasgos identitarios de peso al interior de esta organización sostenidos como premisas de relieve no sólo por sus organismos de dirección sino también, de distinta manera, por el conjunto de su militancia en la cotidianeidad. En primer lugar, la defensa de una concepción obrerista, antiburocrática e insurreccional. Como se analizó en trabajos previos (González, 2006; Pozzi y Schneider, 2000; Werner y Aguirre, 2007), esta corriente definió al proletariado industrial como el sujeto social revolucionario por excelencia y, por ende, su objetivo consistió en lograr una inserción en este sector, específicamente en organismos de lucha tales como las comisiones internas y los cuerpos de delegados a partir de la disputa de su dirección a las conducciones existentes. Desde ya, sostener una política de militancia en el seno de la clase obrera no fue patrimonio exclusivo del PST. Su particularidad consistió en el énfasis puesto, en primer lugar, en una concepción antiburocrática en torno a las formas organizativas y a las metodologias de participación políticosindical de esta clase y, por otro lado, en la apuesta al insurreccionalismo como perspectiva estratégica. Este rasgo asimiló a esta corriente al fenómeno del clasismo, al tiempo que le permitió diferenciarse de aquellas dirigencias sindicales peronistas transformadas en conduc- 
ciones burocratizadas. Por su parte, la retórica insurreccional con el respectivo papel otorgado a las masas en la visualización de un proceso revolucionario la distinguió de aquellas concepciones foquistas y guerrilleristas (Mangiantini, 2014a). La materialización de esta concepción se vislumbró especialmente en el fenómeno de la proletarización de su militancia, lo que supuso un vuelco masivo a la actividad fabril de una importante cantidad de sus miembros provenientes de otros sectores como el estudiantado (Mangiantini, 2014b).

El segundo rasgo identitario lo compuso su concepción internacionalista. Acorde a un bagaje trotskista, la dirección del PST pugnó por la construcción de una tendencia internacional que disputara la dirección de la IV Internacional. Ésta, desde finales de los años 60, sostuvo mayoritariamente un apoyo a las vertientes guerrilleristas o foquistas como estrategia para el derrotero de la lucha de clases en Latinoamérica. En esta línea, la profundización de los vínculos con el Socialist Workers Party (SWP) de Estados Unidos, los frecuentes viajes a diversos países latinoamericanos para el establecimiento de relaciones políticas, la edición de una publicación internacional (Revista de América), la participación de militantes de otros países en las instancias de formación política y escuelas de cuadros en Argentina, o bien la constante discusión (en el marco de cada organismo partidario) de diversas problemáticas pertinentes a distintos procesos políticos mundiales fueron algunos de los ejemplos de la puesta en práctica de esta concepción internacional de la militancia. ${ }^{1}$ De hecho, el PST y el SWP de Estados Unidos, desde 1972, impulsaron una corriente minoritaria en el seno de la IV Internacional que fue trascendental para la adopción del partido argentino de las temáticas y reivindicaciones analizadas en este trabajo (Bensaïd, 2008: 114). Esta idiosincrasia implicó una delimitación teórico-conceptual en el seno del movimiento de masas tanto del bagaje nacionalista sostenido por el peronismo como así también del PC que comulgaba con la concepción en torno a la posibilidad de un sostenimiento exitoso del socialismo en un solo país.

Una tercera característica identitaria se relacionó con la actitud esbozada por la militancia del PST hacia la clase obrera peronista. Esta corriente provocó una ruptura dentro de una izquierda argentina históricamente caracterizada por un antiperonismo acérrimo que incluso

1. "Proyecto de resoluciones", VI Congreso Nacional del PRT-LV, septiembre de 1971, pp. 2-3; "Informe sobre viaje a L.A. - Boletín Interno de agosto de 1971"; VI Congreso Nacional del PRT, septiembre de 1971, pp. 1-4; "Orden del día del C.E.", Comité Ejecutivo del PRT-LV, 21 de enero de 1970, p. 2; "Memorándum sobre la revista", Comité Ejecutivo del PRT-LV, 1970, p. 1; "Informe de actividades", Comité Central del PRT-LV, 1970, p. 3; "Orden del día del CC", Comité Central del PRT-LV, 17 de abril de 1971, pp. 4-5. 
la llevó a confluir con organizaciones patronales o conservadoras como modo de oposición. Diferenciándose del movimiento peronista y de aquellas características que lo representaban tales como el verticalismo, el policlasismo, el paternalismo o la metodología de sus cúpulas sindicales, buscó desarrollar una actitud de acercamiento y comprensión hacia la enorme cantidad de obreros que se identificaban con esta propuesta. En el marco de la resistencia obrera al golpe militar de 1955, la acción más notoria practicada como corriente consistió en llevar a cabo la táctica del entrismo en el movimiento peronista, específicamente en sus estructuras sindicales, lo que implicaba el ingreso de los militantes a una organización con una ideología diferente a la propia pero con profundo arraigo en los sectores trabajadores con el fin de provocar un viraje ideológico de sus adherentes hacia la izquierda. Con esta orientación, editó el periódico Palabra Obrera, utilizado como herramienta para relacionarse con distintos sectores fabriles (Camarero, 1997). Independientemente de su éxito, esta estrategia generó la concepción de que, desde una militancia trotskista, podría producirse un diálogo hacia una clase obrera peronista.

Un último rasgo identitario, eje del presente trabajo, recae en la apertura de esta organización a la recepción e inclusión de nuevos idearios mayormente ajenos a la cotidianeidad de la izquierda argentina de entonces. Su amplitud temática excedió a las consignas estrictamente economicistas y, como ejemplo de ello, se destacan reivindicaciones tales como la preocupación por la "liberación de la mujer", cierta defensa a la homosexualidad y el interés por forjar relaciones de género antagónicas a aquellas cotidianas en el derrotero de la cultura hegemónica. No obstante, como se verá, ninguna de estas problemáticas atravesó al PST sin tensiones ni contradicciones.

\section{Las militancias del PST en torno a la liberación de la mujer}

Una temática que este partido comenzó a ponderar hasta convertirse en un rasgo identitario de fortaleza consistió en la reivindicación en torno a la liberación de la mujer, problemática en ningún modo unívoca pero que aún así interesó a la organización. Este tópico no constituyó un terreno claro en objetivos, motivos ni estrategias. De hecho, fue un asunto predilecto de la prensa masiva que lo retrató de múltiples y contradictorias formas, la más de las veces de modo despolitizado y como sinónimo de las frivolas transformaciones sociales, culturales y económicas vividas por las mujeres de la burguesía desde mediados del siglo XX; cuando no lo construyó como objeto de burla. De modo que abrazar una militancia bajo este nombre supuso el desafio como par- 
tido de conseguir estabilizar algunos sentidos y desterrar otros lo que, además, debe ponerse en valor si se considera el rechazo que ante esta problemática manifestaron diversas expresiones de la izquierda tales como el PC o diferentes estructuras político-militares.

La militancia en favor de la liberación de la mujer se tornó parte de una militancia activa en los momentos de transición entre la disolución del PRT-LV y los inicios del PST, entre 1971 y 1972. La principal explicación en torno a su profundización se encuentra en la influencia que sobre la organización argentina ejerció el SWP de Estados Unidos, cuyo programa político abordaba reivindicaciones pertinentes a estas temáticas. ${ }^{2}$ A partir del rechazo conjunto a la estrategia militarista adoptada por una mayoría de la IV Internacional, el SWP y la corriente argentina estrecharon lazos que trajeron consigo frecuentes viajes e intercambio de experiencias. Así, el PST adoptó temáticas antes secundarias tales como la importancia del papel de una juventud radicalizada con una retórica antiimperialista y antibélica o el carácter combativo que podrían jugar las minorias étnicas. No obstante, la problemática en torno a la liberación de la mujer fue, sin dudas, la reivindicación que mayor impacto generó. ${ }^{3}$ A su vez, puede encontrarse otra explicación de esta iniciativa dada la emergencia en el mundo occidental de un ascendente movimiento feminista paulatinamente reflejado en publicaciones y medios de comunicación de importante recepción (Trebisacce, 2014).

Cabe señalar que, en este periodo, diversas organizaciones forjaron sus propias entidades femeninas como, por ejemplo, en estructuras político-militares tales como el Partido Revolucionario de los Trabajadores y el Ejército Revolucionario del Pueblo (PRT-ERP) con la creación del Frente de Mujeres, o en Montoneros con la Agrupación Evita. No obstante, una característica coincidente de ambas experiencias recayó en que estos frentes fueron creados con el objeto de formación politica de sus mujeres pero no para el desarrollo una militancia específica o feminista. Se trató de agrupaciones femeninas que, al mismo tiempo, se declaraban antifeministas (Grammático, 2011; Martínez, 2009). En este punto radica la diferencia central que esgrimió el PST al abordar esta problemática y por ello la importancia de su análisis para el campo de estudio.

2. El feminismo socialista aseveraba que las categorias del marxismo resultaban insuficientes para la comprensión de las particularidades de la opresión de la mujer pero, al mismo tiempo, rechazaba aquellas reivindicaciones propias de la mujer desligadas de una denuncia al modo de producción capitalista. De ello se desprendía la necesidad de una teoría que contemplara el método histórico y materialista del marxismo combinado con el análisis de las relaciones patriarcales del feminismo radical. 3. "Orden del día del CC", Comité Central del PRT-LV, 17 de abril de 1971, e "Informe internacional", Comité Central del PST, 1972. 
Respecto a la experiencia de este partido, la militancia en torno a la liberación de las mujeres no estuvo ausente de tensiones ni contradicciones. Puede afirmarse que, entre 1971 y 1975, ella atravesó tres momentos diferenciados que supusieron distintas lecturas respecto de cuáles eran las problemáticas específicas de las mujeres y cuáles debian ser las estrategias o políticas de militancia (Trebisacce, 2012, 2013). El primero de ellos, se ubica desde finales de 1971 hasta mediados de 1972 en coincidencia con el proceso formativo del PST. La aparición de Avanzada Socialista como su órgano de difusión semanal incluyó un tratamiento prácticamente constante de la lucha por la "liberación de la mujer". Las primeras referencias se orientaron a analizar la situación de las mujeres en un sentido amplio y no restringido a aquellas comprometidas con la lucha política, sindical o estudiantil. La publicación expresa interés por visibilizar la situación de doble explotación que padecían las mujeres en tanto trabajadoras y amas de casa, pero simultánea y enfáticamente procura analizar y denunciar el papel jugado por los medios de comunicación, la publicidad, la familia y la escuela en la reproducción de un estereotipo femenino pasivo y objeto del placer masculino. ${ }^{4}$ De modo que la novedad teórico-política de estos planteos consistió en producir reivindicaciones en torno a la situación de las mujeres que excedian el bagaje materialista clásico y ponian el acento en elementos subjetivos o en relaciones interpersonales, dentro de un plano no necesariamente económico, que garantizaban la situación desfavorable de las mujeres independientemente de la existencia del capitalismo como sistema. Así, se alertaba sobre la presencia de pautas culturales y familiares, y sobre el rol de los medios de comunicación y la publicidad, como garantes de esta doble opresión. ${ }^{5}$

Se desprende de esta particular perspectiva la influencia que sobre la corriente argentina ejerció el feminismo socialista norteamericano de finales de los 60 y los debates contemporáneos del feminismo local que identificaban la opresión femenina como consecuencia de su sexo y no sólo como efecto de su situación con respecto a las relaciones de producción, lo que redundaba en un antagonismo de clases sexuales (el patriarcado) paralelo al de clases sociales. ${ }^{6}$ Por ello, las feministas radicales denunciaban el trabajo doméstico no sólo como reproducción del

4. "Mujeres en lucha", en Avanzada Socialista (AS), año 1, $\mathrm{n}^{\circ}$ 3, 15 de marzo de 1972, p. 10.

5. "Antes nos vendaban los pies, ahora nos lavan el cerebro", AS, año 1, n 10, 3 de mayo de 1972.

6. Esta perspectiva era sostenida por agrupaciones feministas como la Unión Feminista Argentina (UFA) y el Movimiento de Liberación Feminista (MLF) con quienes algunas militantes del PST entraron en contacto. 
capital sino también en tanto esclavización de las mujeres por parte de sus propios maridos (Molina Petit, 2007). La aceptación de dos sistemas paralelos de opresión, el capitalismo y el patriarcado, le permitió al PST caracterizar positivamente la aparición de organizaciones feministas que luchaban contra la opresión de las mujeres aunque no se implicaran en una militancia anticapitalista. No obstante esta apertura, la linea partidaria sostenía que la liberación femenina no podría ser total sin la liberación del pueblo entero del sistema de explotación capitalista.

Como parte de la puesta en práctica de la política por la liberación de la mujer, el PST desarrolló diversas actividades como, en 1972, la invitación al país a Linda Jenness, candidata a presidente en Estados Unidos por el SWP y militante feminista, quien brindó una serie de charlas y participó de diversos actos. ${ }^{7}$ Con su visita, las luchas de las mujeres ocuparon la primera plana de Avanzada Socialista que comenzó a utilizar abiertamente el término feminismo. Las actividades con esta dirigente permitieron una mayor visualización de la militancia feminista realizada pero, al mismo tiempo, dejaron al descubierto ciertas tensiones que persistian. Así fue como en un reportaje a la candidata se le consultó si entendía que eran viables los movimientos feministas como organizaciones de lucha en sí mismas o si, por el contrario, las mujeres debian pelear en sus respectivos ámbitos laborales por aquellas reivindicaciones comunes a sus sectores. ${ }^{8} \mathrm{El}$ interrogante reflejaba una tensión existente al interior del partido sobre la posibilidad de transformar las reivindicaciones de las mujeres en una politica autónoma de las restantes luchas.

Por fuera de la visita de la candidata norteamericana, el signo más claro de la existencia de una militancia feminista al interior del PST lo brindó la conformación de un grupo, Muchacha, que produjo una publicación homónima y participó de actividades con otros colectivos de mujeres. No obstante, es necesario advertir que dicha publicación no contó en sus páginas ni en sus acciones con una declaración abierta de relación o pertenencia para con la estructura partidaria. De hecho, en Avanzada Socialista se referenció a Muchacha en tercera persona, desmarcándose cualquier vinculación directa con el partido. Asimismo, y como otro signo ambiguo en torno a la apropiación que hacía el PST de su militancia feminista, las integrantes de Muchacha no utilizaban los locales partidarios para sus actividades sino que recurrian a los de otras agrupaciones feministas. Es factible que ello respondiera al intento partidario de respetar la independencia de su militancia femi-

7. "Linda levanta cuatro banderas", AS, año 1, n 13, 24 de mayo de 1972, p. 6.

8. "Linda Jenness habla para Avanzada Socialista", AS, año1, $\mathrm{n}^{\circ} 13,24$ de mayo de 1972, p. 7 . 
nista evitando convertirse en obstáculo para el acercamiento de mujeres que quisieran desarrollar esta actividad específica sin comprometerse con una organización revolucionaria. También es probable que fuera resultado de un posicionamiento tímido por parte del partido, en lo que respecta a la enunciación pública, en torno a una militancia que resultaba controvertida en el espectro de las izquierdas. No obstante, vale destacar que esta estrategia fue desplegada por el PST también a nivel obrero (con la conformación de agrupaciones sindicales no integradas exclusivamente por militantes partidarios) y a nivel juvenil con la creación de la Juventud Socialista de Avanzada en la que los jóvenes podian militar sin ser aún considerados parte orgánica de la estructura.

Por otra parte, para la caracterización global de este período merece mención el hecho de que entre la militancia circularan textos actualizados en torno a la sexualidad, incluso entre quienes no se interesaban en participar directamente de las actividades feministas. Se compartian, por ejemplo, el Informe Hite (una investigación de la escritora y sexóloga Shere Hite que hacia hincapié en la sexualidad y el placer femenino); los estudios sobre las técnicas sexuales de William Masters y Virginia Johnson; La mujer: ¿esclava de la historia o historia de la esclava?, de Nancy Hollander; la producción de Simone de Beauvoir y escritos de militantes feministas de Estados Unidos, como Problemas de la liberación de la mujer de Evelyn Reed (que el PST editó en Argentina). Esto permite inferir un interés generalizado en torno a las tendencias que bregaban por una (relativa) mejor situación para las mujeres, como era el caso en los discursos en boga sobre la sexualidad. También, según revelan algunas entrevistadas, merecieron charlas entre compañeros asuntos como el amor libre y las contradicciones de la monogamia, a pesar de no constituirse como temas a tratar en las reuniones partidarias.

Un segundo momento puede señalarse entre finales de 1972 y los últimos meses de 1974. En este período Avanzada Socialista refleja que la preocupación en torno a la militancia de las mujeres quedó circunscripta a las noticias sobre las campañas electorales acaecidas en 1973, particularmente en la primera en la que Nora Ciapponi fue candidata a la vicepresidencia por el PST. Su inclusión en la fórmula dio lugar a una denuncia pública de la situación desfavorable de las mujeres. ${ }^{9}$ Simultáneamente, la plataforma electoral incluyó un bloque de reivindicaciones pertinente a la lucha por su liberación con el sostenimiento de consignas tales como la legalización y gratuidad del aborto, la venta libre de remedios anticonceptivos, la protección estatal de la madre soltera y la supresión de las diferencias jurídicas entre los hijos

9. "Nora Ciapponi habla de la mujer", $A S$, año 1, $\mathrm{n}^{\circ}$ 45, 18 de enero de 1973; "Nora Ciapponi defiende a la mujer", $A S$, año 1, n 50, 22 de febrero de 1973. 
legitimos y los naturales, la igualdad de derechos de la familia legitima y la naturalmente constituida, la apertura de guarderias infantiles durante todo el dia, la igualdad salarial entre hombres y mujeres ante las mismas tareas, la participación obligatoria de las mujeres en todos los organismos sindicales en proporción a las labores femeninas en las ramas de producción y la supresión de toda legislación discriminatoria entre hombres y mujeres. ${ }^{10}$ Determinadas consignas como la igualdad salarial o la apertura de guarderias en las fábricas eran medianamente habituales dentro del repertorio de las organizaciones revolucionarias, pero el sostenimiento de reclamos como el derecho al aborto o la gratuidad de las pastillas anticonceptivas (en un contexto de recelo y discusión en torno a este método) fueron paradigmáticas como un rasgo distintivo (Bellucci, 2012). Tras la campaña electoral, estas temáticas quedaron más opacadas hasta que en 1974 el PST tomó como reclamo la oposición al decreto de prohibición de venta de anticonceptivos lanzado por el gobierno de María Estela Martínez de Perón. ${ }^{11}$

Finalmente, se identifica un último momento desde fines de 1974 hasta los últimos meses de 1975, en el que se ve al PST experimentar una disputa y redefinir el sentido de su militancia feminista. En este período, Avanzada Socialista inauguró la sección "Mujer" en la que pueden verse operar las renegociaciones de sentidos. En las primeras notas mencionaba la existencia de grupos feministas que rechazaban la militancia de izquierda, como la Unión Feminista Argentina y el Movimiento de Liberación Feminista, a quienes se les reconocía su trabajo en la concientización de las mujeres aunque se advertía sobre las "exageraciones cometidas". Coincidiendo con este periodo, en febrero de 1975, una minuta interna del partido titulada Minuta sobre la campaña de liberación de la mujer recuperaba no sólo los antecedentes del movimiento feminista en el mundo y en Argentina sino que orientaba el foco de sus críticas a los discursos emanados por los medios masivos de comunicación en torno a la mujer, especialmente dirigidos a la población de clase media (Trebisacce, 2013). Asimismo, se sostenía que la lucha feminista era útil y no un impedimento o una distracción para el combate partidario contra el capitalismo. Aquí aparece un rastro distintivo del PST en comparación con otras organizaciones como el PRT-ERP o Montoneros, que caracterizaron al feminismo como una

10. "Los comités ejecutivos del Partido Socialista Argentino y del PRT (La Verdad) afirman", Comité Ejecutivo del PRT-LV, 1972, pp. 5-6.

11. "Más hijos ¿Quién los alimenta? No al decreto contra los anticonceptivos", AS, año 2, n' 96, 20 al 27 de marzo de 1974, p. 6; " "La ley de los anticonceptivos es una medida más de tipo represivo" nos dijo Cipe Linkovsky", AS, año 2, nº 97, 28 de marzo al 5 de abril de 1974, p. 4. 
expresión de la burguesía y no como una herramienta válida para la lucha contra el capital.

Ahora bien, desde principios de 1975, la sección adoptó otro perfil y comenzó a representar exclusivamente la realidad de las mujeres inscriptas en luchas sindicales o estudiantiles. Se trató de un redefinición rotunda respecto de lo que entendería el partido como militancia específica de las mujeres, que supuso la clausura de la relación con los feminismos no alineados en una lucha anticapitalista y una depuración de cierta militancia feminista interna del partido. Por ejemplo, aparecieron en la sección "Mujer" notas que celebraban la participación de las mujeres y esposas en el conflicto de Villa Constitución, en el que el PST participó de su comisión de mujeres, o en la huelga general lanzada contra la política de ajuste conocida como el Rodrigazo. ${ }^{12}$ La sección se convirtió en un llamado a las mujeres a participar de la lucha sindical o partidaria. Se publicaron especialmente testimonios de mujeres participantes de gremios o agrupaciones estudiantiles que daban cuenta de las dificultades que tenían por su condición de mujeres para emprender la militancia. ${ }^{13}$ En ocasiones, se reproducian informes históricos sobre las experiencias de militantes mujeres en otros lugares del mundo como Vietnam o China. ${ }^{14}$

En julio de 1975, en un documento interno, se sostuvo que "el trabajo de la mujer pasa esencialmente alrededor de la lucha de clases, en forma combinada y no como movimiento paralelo e independiente". ${ }^{15}$ En otras palabras, el PST redefinió cuáles eran los problemas específicos de las mujeres y los vinculó directamente a las reivindicaciones sindicales o las problemáticas de cada gremio en particular, tales como los malos tratos, la discriminación, los problemas con las guarderías en los trabajos, entre otros. En este sentido, esbozó consignas como el reclamo para que se decrete la obligación de las patronales de contratar un $50 \%$ de personal femenino, o bien la necesidad de conformar comisiones femeninas por fábrica para controlar el cumplimiento de los derechos de las mujeres dentro de cada ámbito laboral. A su vez, denunció la política de protección familiar sostenida por el gobierno peronista que prohibia los

12. "Así participamos en las luchas obreras. "Mujeres son las nuestras...", AS, año 4, $\mathrm{n}^{\circ}$ 141, 5 de abril de 1975; "Las mujeres con la CGT", AS, año 4, n 152, 5 de julio de 1975 .

13. "Elecciones sindicales. Incorporemos mujeres a las listas, levantemos un programa para la mujer", $A S$, año 4, $\mathrm{n}^{\circ} 156,1$ de agosto de 1975.

14. "La mujer en el mundo. Vietnam", AS, año 4, n 172, 21 de noviembre de 1975; "La mujer en el mundo. China", $A S$, año 4, n 174, 5 de diciembre de 1975.

15. "Minuta sobre el trabajo de la mujer", Comité Central del PST, 18 de julio de 1975, pp. 5-6. 
anticonceptivos y el aborto dado que, según el análisis de esta corriente, ambas esferas daban cuenta de un proyecto que pretendia reconvertir el papel de la mujer en ama de casa y cuidadora de los hijos. ${ }^{16}$

En coincidencia con esta línea, se trató del período con una mayor cantidad de actividades relacionadas con la temática de la mujer tanto hacia el afuera como para la propia estructura partidaria. Los balances dan cuenta de la realización de un notorio número de cursos dentro de las instancias de formación militante del partido; el sostenimiento de una sección permanente en el periódico, artículos en diversas revistas sindicales; la formación de un equipo partidario dedicado a este tópico; la organización de un archivo partidario sobre el tema; edición de volantes, folletos y libros; organización de mesas redondas; e intento de constitución de la Agrupación de Mujeres Socialistas. ${ }^{17}$

La vuelta del peronismo al poder y el retorno al sistema electoral en 1973 no cerrarian las profundas contradicciones político-sociales ni la crisis abierta años atrás. El giro a la derecha del gobierno peronista con la conformación de grupos paramilitares que, al amparo del poder estatal, emprendieron una encarnizada persecución contra el activismo partidario, sindical y juvenil complejizó este convulsionado contexto. Esta antesala del terrorismo de Estado por venir fue un quiebre para la militancia del PST alrededor de estas temáticas dado que su accionar político pasó a desarrollarse casi integramente de modo clandestino y a resguardo de la represión, por lo que las campañas públicas de esta índole dejaron lugar a otro tipo de metodologías mayormente subterráneas.

\section{Las concepciones alrededor de la homosexualidad}

Por aquellos años la homosexualidad se convirtió en un tema medianamente destacado, no tanto por una militancia homosexual que no conseguía ser muy numerosa, sino porque en el contexto cultural de la denominada "revolución sexual" era caracterizada "como una patología que requería intervención" (Trebisacce, 2015). Esta revolución, habitualmente asociada y circunscripta a la aparición de la píldora anticonceptiva, fue en realidad un proceso más complejo que consistió en la circulación masiva de discursos pseudocientíficos en torno a la sexualidad placentera y no reproductiva. Se difundieron en libros, notas de diarios, artículos y charlas, explicaciones científicas sobre la importancia del placer femenino en la vida sexual en pareja (heterosexual) y, simultáneamente, se sostuvieron argumentos que recrudecian la pato-

16. "Minuta sobre la campaña de liberación de la mujer", Comité Central del PST, 11 de febrero de 1975, pp. 7-8.

17. "Minuta sobre el trabajo de la mujer", ob. cit., pp. 1-2. 
logización de las prácticas homosexuales (Cosse, 2009 y 2010; Felitti, 2012; Trebisacce, 2015).

Desde el campo más acotado de las izquierdas, el rechazo a la homosexualidad tenía otras motivaciones. En los regímenes del socialismo real, la homosexualidad no fue admitida sino considerada un peligro social bajo el argumento de ser caracterizada como un producto de contenido burgués y fascista (García Valdés, 1981: 107). En este marco, los partidos comunistas y sus pares maoístas sostuvieron internacionalmente una posición crítica y de rechazo a estos reclamos esbozando caracterizaciones que identificaron la homosexualidad con diversos tipos de desviaciones ajenas a la vida cotidiana del proletariado.

En Argentina, la condena a la homosexualidad al interior de organizaciones partidarias y político-militares fue un fenómeno extendido. Sin embargo, una excepción la constituyó la estructura política encabezada por Moreno, que sostuvo su rechazo a la discriminación y opresión por orientación sexual. Aunque es necesario aclarar que, a diferencia de la problemática en torno a la liberación de la mujer, la defensa a las orientaciones sexuales disidentes fue más bien una actitud y un posicionamiento sostenido internamente como corriente que un programa político defendido públicamente.

A nivel orgánico la temática se desarrolló de un modo laxo e inconstante. Su principal expresión fue la relación forjada entre esta corriente y el Frente de Liberación Homosexual (FLH), organización surgida en 1968, conducida por Héctor Anabitarte, un militante expulsado del Partido Comunista justamente por su orientación sexual (Bilbao, 2012: 23-32). La vinculación entre el FLH y la corriente dirigida por Moreno se produjo por diversas vías. Una de ellas fue a través de la participación de algunos militantes en ambas estructuras, como fue el caso de Néstor Perlongher quien, a partir de su militancia en el FLH, se vinculó luego con el PST. Otra forma de relación se produjo a partir de la realización de campañas conjuntas por diversas temáticas particulares tales como, por ejemplo, la derogación del decreto que prohibía la información y difusión de métodos anticonceptivos. El retorno del peronismo profundizó el lazo entre el PST y el FLH, dado que parte de la militancia homosexual aspiraba a que la llegada de Cámpora al poder significara un viraje en la politica represiva hacia ellos. Sin embargo, la continuidad de una legislación persecutoria por parte del gobierno peronista y el rechazo de otras fuerzas de izquierda a sostener sus reivindicaciones hizo que el PST fuera uno de los pocos apoyos orgánicos en este período (Benisz y Castells, 2009: 117; Bellucci, 2010).

Independientemente de estas puntuales relaciones y de las declaraciones de aceptación, esta temática no se profundizó. Ello redundó en ciertas tensiones acerca de cómo dinamizar este tipo de reivindicaciones. 
Más adelante, la dirigencia de esta corriente señalará que brindarle al homosexual una entidad particular dentro de la organización era una política errónea para la defensa de sus derechos porque se produciría una segregación dentro de la misma estructura partidaria. Esta concepción se puede analizar de un reportaje realizado a Moreno:

-Yo considero a la homosexualidad algo tan normal que me opongo a hacer propaganda. [...] [Daniel] Guérin alerta a los homosexuales contra su tendencia a hacer de su liberación un fin en sí mismo, y que el gran problema que debe plantearse todo militante es la transformación de la sociedad. Un compañero homosexual, dirigente del partido brasileño, queria hacer una corriente dentro del partido a favor de la homosexualidad. Yo me opuse, justamente porque considero a la homosexualidad tan normal como la heterosexualidad. Supongamos que se crea una corriente así dentro del partido, con derechos de fracción. Quiere decir que en los locales habría salitas, cada una con su cartel: "Hombres con Mujeres", "Hombres con Hombres", "Mujeres con Mujeres", y cada fracción tendría su boletín.

-Pero los homosexuales son reprimidos, los heterosexuales no.

-Ah, no, eso es completamente distinto. Dentro de la sociedad luchamos a muerte contra la opresión de los homosexuales y todo tipo de opresión: nacional, racial, etcétera. Yo me refería a que me opongo a hacer ese tipo de actividad hacia el interior del partido. Hacia afuera sí combatimos la opresión de los homosexuales, que para mí es una colateral de la opresión de la mujer (S/A, 1986: 124-125).

Este modo de concebir la relación entre la homosexualidad, su militancia y el activismo revolucionario no siempre fue compartido por aquellos que encabezaban las luchas por tales reivindicaciones para quienes estas posturas suponían una minimización o relego de dichas problemáticas. Pese a lo innovador y arriesgado que era para un partido revolucionario abrazar una militancia de ese tenor en ese contexto, la aceptación que la organización profesaba sobre la homosexualidad se producía junto y simultáneamente a la (clásica) invisibilización de la misma, lo que se manifestó en una cierta y temerosa prudencia al respecto. Ello se vuelve más evidente si se contrapone con la experiencia de la militancia feminista. La posición en torno a la lucha de los homosexuales no se transformó en una militancia activa ni se exteriorizó en su bagaje programático, lo que expresa determinadas contradicciones que el PST no consiguió saldar. 


\section{Familia(s), partido y relaciones sexo-afectivas disidentes}

El último aspecto que se abordará en este trabajo pretende explorar las tensiones desarrolladas entre la estructura partidaria y las familias de sus militantes, por un lado, y, por otro, las relaciones sexo-afectivas no tradicionales practicadas entre los miembros de la organización.

Un primer aspecto a resaltar fue la frecuente tensión entre la militancia revolucionaria y las estructuras familiares. Para algunas organizaciones se trató de una cuestión pragmática dado el problema de la seguridad, producto de la represión, que volvía innecesarias otras argumentaciones para el distanciamiento y la ruptura con formas familiares tradicionales caracterizadas de pequeño burguesas. En el caso de PST estas explicaciones ocuparon un lugar central, probablemente porque las experiencias de clandestinidad fueron más tardias. Si bien, a diferencia de otras organizaciones, esta corriente tuvo una política de menor intromisión en la dinámica doméstica de sus militantes, la presencia de un entorno familiar (ajeno a la misma organización) fue percibida, de todos modos, como factible de conflictos. Un documento que sirve como ejemplo relacionaba las deficiencias de un dirigente de un equipo partidario con las características de su entorno familiar.

Estos aspectos negativos de ambos compañeros se encuentran firmemente cristalizados, debido a la organización de su vida: concretamente su estructura matrimonial que, en vez de ser un trampolín para la actividad y la elevación política, es un ordenamiento cerrado [...] y determina la forma de militar y de sentir la militancia de los compañeros. Debemos caracterizar esa estructura como pequeño-burguesa, siempre que aclaremos que la definimos por su dinámica. Es decir, no es materia de crítica ni el nivel de vida, ni la cantidad de artefactos, ni el número de habitaciones de la casa, ni mucho menos, su derecho a la vida privada ni a la intimidad personal, sino al rol conservador y antirrevolucionario -sólo por eso pequeño burgués- de esa estructura personal. ${ }^{18}$

Según este análisis, una estructura familiar marcada por la rutina y la pasividad era perjudicial para un dirigente porque trasladaba tales características a su actividad militante. Simultáneamente, el núcleo familiar era percibido como un obstáculo para la posibilidad de captación del proletariado y para el desarrollo férreo de una práctica política. Cuando se ponian en práctica las estrategias de inserción entre los trabajadores, el acercamiento a la estructura familiar (con actividades

18. "Balance de Capital 1970", Comité Ejecutivo del PRT-LV, febrero de 1971, pp. 3-5. 
que incluian al entorno del obrero) era un elemento ponderado dado que el ingreso a una organización revolucionaria por parte del trabajador conllevaba una alteración de su dinámica doméstica que, a partir de estas prácticas, se buscaba minimizar en su impacto.

Esta característica puede transformarse en una explicación acerca de por qué, al interior de esta corriente, eran bien consideradas las relaciones de pareja entre los propios militantes. Se argumentaba que la pareja integrada por un militante con alguien externo se convertía en una relación factible de contradicciones y conflictos mientras que, por el contrario, la unión de dos militantes podía redundar en un equilibrio de tipo "biológico", sentimental, intelectual, personal y político partidario. ${ }^{19}$

En estos años se experimentó un cambio de paradigma en torno a las relaciones de parejas dado que el modelo de pareja tradicional, organizado bajo la autoridad del hombre y la domesticidad de la mujer, era reemplazado por uno más moderno, resultado del amor, el compañerismo, la paridad y la complementariedad del varón y la mujer (Cosse, 2006). Este modelo fue el que tuvo mayor presencia entre aquellos militantes que impugnaron las experiencias de los matrimonios autoritarios experimentados por sus padres. Ahora bien, ello suponía no sólo parejas heterosexuales sino también parejas unidas por amor en un vínculo verdadero que no podía ser otra cosa que monogámico.

En relación con ello, aparecen en el PST experiencias poco extendidas en otras organizaciones. Desde sus propias prácticas algunos militantes del partido cuestionaron, no sin contradicciones, los imperativos monogámicos que pesaban sobre las parejas en general y las parejas militantes en particular. Así, se extendió una revisión de la idea de pareja y una recepción a la diversidad de las relaciones humanas con el consecuente cuestionamiento a la monogamia como un valor en sí mismo. Estas experiencias inéditas se tensionaban con otras reivindicaciones que sostenía el partido en torno a lo positivo de las relaciones duraderas y estables, dado que se asociaba la ausencia de una pareja concreta y la proliferación de relaciones por parte del militante con una práctica propia de un consumismo capitalista trasladada al terreno sexual. Según Moreno, la "liberación sexual" en el marco de una sociedad capitalista y no socialista se transformaría finalmente en otro fenómeno del consumo (S/A, 1986). Sin embargo, entre las filas de la militancia del PST tuvieron lugar ensayos de otros modos de relaciones sexo-afectivas que eran pequeñas revoluciones para aquellos años. Estas experiencias, al igual que las concepciones en torno a la homosexualidad, no se convirtieron en consignas programáticas pero sí merecen mención porque fueron posibles dentro de este partido, probablemente como efecto de

19. "Moral bolche o espontaneísta" [Documento de Nahuel Moreno], 1969. 
la capacidad, evidenciada en aquellos años, de dar lugar a experiencias no necesariamente bien recibidas en el campo de la militancia.

\section{Conclusiones}

El PST entre los años 1971 y 1975 fue escenario de una serie de militancias (feministas), posicionamientos (respecto de la homosexualidad) y experiencias de relaciones sexo-afectivas disidentes (en relación a la monogamia) que fueron prácticamente inéditas en la militancia de entonces, fuertemente marcada por la aceptación de valores positivos en la equidad y armonía en las parejas, la monogamia y la heterosexualidad. Ello se convirtió en un componente identitario y en un rasgo excepcional, si se realiza un estudio comparativo con la militancia revolucionaria del mismo período. Aunque, si bien es cierto que la apertura a ciertas temáticas como "la liberación de la mujer", el reconocimiento de la diversidad sexual o los intentos de diferenciarse de la estructura familiar y social existente no se produjeron sin tensiones ni contradicciones, es importante resaltar que esta experiencia se convirtió en un antecedente de relieve para las luchas que, sobre estas problemáticas, se desarrollarían desde los años 80 dinamizándose con mayor fluidez que en esta coyuntura.

Al mismo tiempo, el reflejo de esta experiencia es prueba de la existencia, aunque de forma embrionaria, de la relación forjada en estos años entre la izquierda orgánica y diversos tipos de movimientos de luchas específicas (como en este caso, los colectivos de mujeres o los nacientes movimientos de homosexuales) que, a diferencia de lo esgrimido por buena parte de la bibliografia pertinente, no tuvieron una dinámica de absoluta separación entre ambas instancias sino que es posible visualizar la existencia de una incipiente y molecular retroalimentación entre los diversos actores. La presencia de estos relacionamientos merece una profundización aún pendiente.

Por último, se desprende de este análisis una reflexión abierta. Los estudios sobre los años 60 y 70 fueron atravesados por diversos intentos de conceptualizar a sus actores radicalizados. Determinados abordajes sobre la militancia revolucionaria utilizaron el criterio de identificación y subdivisión entre una "izquierda tradicional" (IT), representada por aquellos partidos politicos de tradición y estructura marxista-leninista, y la presencia de una "nueva izquierda" (NI), marcada por la aparición de flamantes actores, especialmente las organizaciones politico-militares (Hilb y Lutzky, 1984; Zolov, 2012). En ocasiones, se afirmó que aquellas estructuras pertenecientes a la NI presentaron una mayor democracia interna y una praxis más horizontal que los partidos tradicionales. En otras producciones, se identificó a la IT como una corriente refor- 
mista, pacifista y electoralista, mientras que la NI produjo un nuevo significado y valorización del uso de la violencia. La apelación a una NI también remitió a aquellas estructuras que pugnaron por la fusión de un ideario marxista con otras tradiciones politicas como el peronismo, o bien a las organizaciones que, si bien no asumieron la lucha armada, no desdeñaron el papel de la violencia como modo de alcanzar la transformación socialista (Terán, 1991; Tortti, 1999). En relación con ello, el abordaje conceptual de una estructura como el PST supone la presencia de interrogantes. Posicionada, teórica y estratégicamente, a la izquierda del comunismo y el socialismo vernáculo, se trató de una organización que puso en práctica un bagaje organizativo propio de la tradicional izquierda marxista-leninista con la consecuente aplicación de los preceptos del centralismo democrático. Al mismo tiempo, se trató de una corriente que rechazó la conformación de organizaciones simultáneamente políticas y militares negando el uso de la violencia política por fuera de los organismos creados por el propio activismo. No obstante ello, y paralelamente, el presente artículo dio cuenta de una estructura que sostuvo reivindicaciones hasta entonces no abordadas por el conjunto de la izquierda argentina tradicional y que, de hecho, fueron asimiladas al contenido propio de la NI, lo que permitiria sostener la existencia de un interrogante sobre la utilización de estas categorías para realizar una tipología apropiada sobre la enorme diversidad de actores que coexistieron en esta convulsionada coyuntura.

\section{Bibliografia}

Bellucci, Mabel (2010), Orgullo. Carlos Jáuregui, una biografía política, Buenos Aires: Emece.

- (2012), "Revolución social y revolución sexual", Herramienta. Revista de debate y crítica marxista, año XVI, $\mathrm{n}^{\circ} 50$.

Benisz, Carla y Mario Castells (2009), "Néstor Perlongher, poesía y militancia. Intervenciones políticas en el barroso estuario de la polis", Actas I Jornadas de Historia de la Critica en la Argentina, FFyL (UBA).

Bensaïd, Daniel (2008), Trotskismos, Portugal: Combate.

Bilbao, Bárbara Soledad (2012), "Frente de Liberación Homosexual (19711976): Prácticas comunicacionales de resistencia y resignificaciones en la historia reciente", Questión, vol. 1, nº 33, pp. 23-32.

Camarero, Hernán (1997), "Una experiencia de la izquierda en el movimiento obrero. El trotskismo frente a la crisis del peronismo y la resistencia de los trabajadores (1954-1957)”, Razón y Revolución, $\mathrm{n}^{\circ} 3$.

Cosse, Isabella (2006), "Cultura y sexualidad en la Argentina de los sesenta: usos y resignificaciones de la experiencia transnacional", Estudios Interdisciplinarios de América Latina y el Caribe, vol. $17, \mathrm{n}^{\circ} 1$.

- (2009), "Los nuevos estereotipos femeninos en los años 60 y 70: de la 
mujer doméstica a la joven liberada", en A. Andújar, De minifaldas, militancias y revoluciones. Exploraciones sobre los 70 en la Argentina, Buenos Aires: Luxemburg.

- (2010), Pareja, sexualidad y familia en los años sesenta, una revolución discreta en Buenos Aires, Buenos Aires: Siglo XXI.

Felitti, Karina (2012), La revolución de la píldora. Sexualidad y politica en los setenta, Buenos Aires: Edhasa.

García Valdés, Alberto (1981), Historia y presente de la homosexualidad, Madrid: Akal.

González, Ernesto (coord.) (2006), El trotskismo obrero e internacionalista en la Argentina, tomo 4: El PRT La Verdad ante el Cordobazo y el clasismo. Volumen 1 (1969-1971), Buenos Aires: Fundación Pluma.

Grammático, Karin (2011), Mujeres montoneras. Una historia de la Agrupación Evita, 1973-1974, Buenos Aires: Luxemburg.

Hilb, Claudia y Daniel Lutzky (1984), La nueva izquierda argentina: 19601980 (Politica y violencia), Buenos Aires: CEAL.

Mangiantini, Martín (2014a), El trotskismo y el debate en torno a la lucha armada. Moreno, Santucho y la ruptura del PRT, Buenos Aires: El Topo Blindado.

Mangiantini, Martín (2014b), "Clase y partido. Surgimiento, proletarización y militancia fabril del PRT - La Verdad (1968-1972)", Archivos de Historia del Movimiento Obrero y la Izquierda, año 2, no 4, pp. 31-52.

Martínez, Paola (2009), Género, politica y revolución en los años setenta. Las mujeres del PRT-ERP, Buenos Aires: Imago Mundi.

Molina Petit, Cristina (2007), "El feminismo socialista estadounidense desde la "nueva izquierda". Las teorias del sistema dual (capitalismo + patriarcado)", en Celia Amorós y Ana de Miguel, Teoría feminista: de la Ilustración a la globalización. Del feminismo liberal a la posmodernidad, Madrid: Minerva, pp. 147-187.

Pozzi, Pablo y Alejandro Schneider (2000), Los setentistas. Izquierda y clase obrera: 1969-1976, Buenos Aires: Eudeba.

S/A (1986), Conversaciones con Nahuel Moreno, Buenos Aires: Antídoto.

Terán, Oscar (1991), Nuestros años sesentas: la formación de la nueva izquierda intelectual en la Argentina, 1955-1966, Buenos Aires: Punto Sur.

Tortti, María Cristina (1999), "Protesta social y "Nueva Izquierda" en la Argentina del Gran Acuerdo Nacional”, en Alfredo Pucciarelli, La primacía de la política. Lanusse, Perón y la Nueva Izquierda en tiempos del GAN, Buenos Aires: Eudeba.

Trebisacce, Catalina (2012), "Aunque algunos se rían de nosotr(o)s... Crónica de las exploraciones en la militancia feminista del Partido Socialista de los Trabajadores (1972-1975)", Temas de Mujeres. Revista del CEHIM, año $8, n^{\circ} 8$, pp. 100-126.

- (2013), "Encuentros y desencuentros entre la militancia de izquierda y el feminismo en la Argentina", Revista Estudos Feministas, vol. 21, n 2, pp. 439-462. 
- (2014) "Revoluciones simbólicas y de militancia en las feministas porteñas de los setenta", en Mónica Tarducci (comp.), Feminismo, lesbianismo y maternidad, Buenos Aires: Feminaria, pp. 7-35.

- (2015) "Una batalla sexual en los setenta: las feministas y los militantes homosexuales apostando a otra economía de los placeres", en Débora D’Antonio (comp.), Deseo y represión. Sexualidad, género y Estado en la historia argentina reciente, Buenos Aires: Imago Mundi.

Werner, Ruth y Facundo Aguirre (2007), Insurgencia obrera en la Argentina. Clasismo, coordinadoras interfabriles y estrategias de la izquierda, Buenos Aires: Ediciones IPS.

Zolov, Eric (2012), "Expandiendo nuestros horizontes conceptuales: el pasaje de una "vieja" a una "nueva izquierda" en América Latina en los años sesenta", Revista Aletheia, vol. 2, nº 4.

$$
* * *
$$

Título: Feminism, sexual diversity and gender relations affective dissidents. Stakes and tensions in the Socialist Workers Party (PST) between 1971 and 1975

Resumen: El presente trabajo tiene como objetivo abordar la dinámica de una organización revolucionaria trotskista, el Partido Socialista de los Trabajadores (PST), entre 1971 y 1975, en lo pertinente a tres temáticas entrelazadas: la militancia feminista sostenida, las concepciones esgrimidas con relación a la homosexualidad y los lazos sexo-afectivos desarrollados dentro de la dinámica partidaria. Se sostiene que el abordaje de dichas problemáticas por parte de esta organización fue un rasgo particular e identitario en la convulsionada coyuntura argentina de los años 70 que la diferenció de otras expresiones revolucionarias. Palabras clave: trotskismo - liberación de la mujer - diversidad sexual - relaciones de género

Abstract: This paper aims to address the dynamics of a revolutionary Trotskyist organization, the Socialist Workers Party (PST), between 1971 and 1975, as appropriate three interwoven themes: feminist militancy sustained, the concepts put forward in relation to homosexuality and sex-affective ties developed within the party dynamics. It is argued that addressing these issues by this organization and identity was a particular feature in the troubled Argentina seventies situation that differed from other revolutionary expressions.

Keyboards: Trotskyism - feminism - sexual diversity - gender relations

Recepción: 2 de marzo de 2015. Aprobación: 11 de julio de 2015 